\title{
Ultrafine particles in urban air and respiratory health among adult asthmatics
}

\author{
P. Penttinen*, K.L. Timonen*, P. Tiittanen*, A. Mirme\#, J. Ruuskanen ${ }^{\natural}$, J. Pekkanen*
}

Ultrafine particles in urban air and respiratory health among adult asthmatics. P. Penttinen, K.L. Timonen, P. Tiittanen, A. Mirme, J. Ruuskanen, J. Pekkanen. (C) ERS Journals Ltd 2001.

ABSTRACT: Airborne particles are associated with adverse health effects and contribute to excess mortality in epidemiological studies. A recent hypothesis proposes that the high numbers of ultrafine $(<0.1 \mu \mathrm{m}$ diameter) particles in ambient air might provoke alveolar inflammation and subsequently cause exacerbations in pre-existing cardiopulmonary diseases.

To test the hypothesis adult asthmatics were followed with daily peak expiratory flow (PEF) measurements and symptom and medication diaries for six months, while simultaneously monitoring particulate pollution in ambient air. The associations between daily health endpoints of 57 asthmatics and indicators of air pollution were examined by multivariate regression models.

Daily mean number concentration of particles, but not particle mass (PM10 (particle mass $<10 \mu \mathrm{m}), \mathrm{PM}_{2.5}-10, \mathrm{PM} 2.5$, PM1), was negatively associated with daily PEF deviations. The strongest effects were seen for particles in the ultrafine range. However, the effect of ultrafine particles could not definitely be separated from other traffic generated pollutants, namely nitric oxide, nitrogen dioxide and carbon monoxide. No associations were observed with respiratory symptoms or medication use.

Particle mass measurements can be strongly influenced by mechanically produced, soil-derived particles, which may not be associated with adverse health effects. Therefore, air quality monitoring should include particle number concentrations, which mainly reflect ultrafine particles.

Eur Respir J 2001; 17: 428-435.
*Unit of Environmental Epidemiology, National Public Health Institute, 70701 Kuopio, "\#Institute of Environmental Physics, University of Tartu, Ülikooli street 18, EE2400 Tartu, Estonia and Dept of Environmental Sciences, University of Kuopio, 70211 Kuopio, Finland.

Correspondence: J. Pekkanen, Unit of Environmental Epidemiology, National Public Health Institute, 70701 Kuopio, Finland

Fax: 35817201265

Keywords: Air pollution asthma

particles

particle size

peak expiratory flow rate

respiratory symptoms

Received: January 272000

Accepted after revision May 282000

This study was supported by the EU ENVIRONMENT and CLIMATE Research Programme Contracts ENV4CT96-0205 and ENV4-CT97-0568 and the Academy of Finland. P. Penttinen was supported financially by the NorthSavo Cultural Foundation.
A number of studies have shown that urban particulate air pollution is associated with declines in peak expiratory flow and increased respiratory symptoms, hospital admissions and mortality from cardiorespiratory causes $[1-6]$. However, the biological mechanism of these effects is unclear. It has been suggested that the high number of particles below $0.1 \mu \mathrm{m}$ in diameter (ultrafine particles) may be responsible for the adverse health effects of particulate air pollution [7-9]. To test this hypothesis the authors conducted a half-year follow-up study with daily peak expiratory flow (PEF) measurements on a group of 57 adult asthmatics. Simultaneously with the health study, an extensive ambient air monitoring campaign was conducted in a central monitoring site.

Existing air quality standards in the European Union use a gravimetric measure of particulate matter $<10 \mu \mathrm{m}$ in aerodynamic diameter PM10, as a basis for standard setting. However, in the subarctic climatic conditions of Finland, high levels of PM10 are frequently caused by resuspended road dust in autumn and spring. A secondary objective of the study was to determine whether the health effects of PM10 measurements (including resuspended road dust) differ from air quality indicators reflecting traffic exhaust.

\section{Material and methods}

The study was conducted in Helsinki, Finland, which is considered to have low air pollution levels compared with most European cities. Characteristic features of air pollution in Helsinki are low ozone $\left(\mathrm{O}_{3}\right)$ levels, occasional episodes of meteorological inversion situations with high air pollution levels, and seasonal episodes of resuspended road dust. The road dust phenomenon is seen mainly during spring, when the streets are dry, the snow and ice on the ground have melted, and the particulate matter deposited on the street during the winter is resuspended. This particulate matter consists mainly of sand spread on the icy roads 
during the winter and matter ground from the road surface by studded tyres. The study was conducted during the winter and spring season (November 1, 1996-April 30, 1997).

The study group consisted of 78 adult asthmatic persons from urban Helsinki. The group was recruited with newspaper announcements, direct mail, and through the local association of pulmonary disabled. Only adult, non-smoking asthmatics were admitted to the group. Asthma diagnosis was confirmed from the sickness insurance card supplied by the Social Insurance Institution of Finland. The entire study group resided within $2 \mathrm{~km}$ of the air quality monitoring site to ensure that the point measurement of pollutants reflects the pollutant exposure of the study subjects as well as possible.

The results of 57 subjects out of $78(73 \%)$ were used for the study. A total of 125 (60\% of possible days) participation days was required for a person to be included in the analysis and this was the reason for exclusion of 20 subjects, most of whom dropped out during the first week. One subject was excluded because of unreliable reporting and one subject because asthma diagnosis could not be confirmed.

The respiratory health of the subjects was monitored daily with PEF measurements and a symptom and medication diary. In addition, the subjects visited the study clinic biweekly to perform a spirometric lung function test. The symptom diary included a numerical (scale $0-3$ ) estimate on the severity of the following symptoms: cough, phlegm, a runny/stuffed nose, awakened by breathlessness, breathlessness, wheezing, attack involving breathlessness and wheezing, and fever. The names, dosages and daily doses of respiratory medication were also recorded in the diary. Finally, the diary included numerical estimates of time spent outdoors, time spent in locations with tobacco smoke, and time spent outside of urban Helsinki. The study subjects measured PEF values every day in standing position immediately after getting up (06:00 - 12:00), after work (14:00 - 18:00) and before going to sleep (18:00-00:00) with a mini-Wright peak flow meter (Airmed; Clement Clarke International, Essex, UK). Each measurement included three blows, and all of them were recorded in the diary. The subjects were advised to do the measurements before taking any medication or having a meal. In addition, a supervised PEF-manoeuvre was done at each biweekly clinic visit to verify correct performance of the measurement. The subjects were also characterised with a standard methacholine challenge test and a skin-prick test with the 13 most common local allergens.

Air pollutants were monitored on a fixed site in central urban Helsinki. Daily variation of particle number concentrations measured at this fixed site reflects well those measured in other sites in urban Helsinki [10]. Particulate air pollution was monitored with five methods. Number concentration of particles in the size range $0.01-10 \mu \mathrm{m}$ were measured continuously with an Electric Aerosol Spectrometer (EAS; University of Tartu, Tartu, Estonia) in 12 size ranges, all of which were added up to get the total particle number concentration (PNC). The first 4 size ranges were added up for NC0.01-0.1 and the next 4 were added up for $\mathrm{NC} 0.1-1$. EAS has been shown to be comparable to other aerosol spectrometers for particle numbers in the submicrometer range, but may overestimate the number of larger particles [11]. For quality control purposes, particle counts were also monitored continuously with a Condensation Nuclear Counter (CNC; TSI Inc, St. Paul, MN, U.S.A.). The correlation coefficient between PNC and particle counts measured by $\mathrm{CNC}$ was 0.98 . Twenty-four hour particle mass concentrations were monitored with single-stage Harvard impactors (Air diagnostics and engineering, Naples, ME, USA) for particles $<10 \mu \mathrm{m}$ (PM10), $<2.5 \mu \mathrm{m}$ (PM2.5) and $<1 \mu \mathrm{m}$ (PM1) in diameter. Coarse particle mass (PM2.5-10) was calculated by subtracting the value of PM2.5 from the value of PM10. The particle monitors were located approximately $50 \mathrm{~m}$ away from major traffic sources in a residential neighbourhood. Gaseous pollutants were measured with continuously recording monitors at the same site. Carbon monoxide (CO) was measured with a CO10M (Environment, Poissy, France), nitric oxide (NO) and nitrogen dioxide $\left(\mathrm{NO}_{2}\right)$ with an AC30M (Environment), sulphur dioxide $\left(\mathrm{SO}_{2}\right)$ with Thermo Environmental model 43 (Thermo Environmental Instruments Inc., Franklin, MA, U.S.A) and $\mathrm{O}_{3}$ with Thermo Environmental model 49 (Thermo Environmental Instruments Inc.). The data for gaseous pollutants and meteorological parameters (wind speed, wind direction, relative humidity, minimum temperature) were provided by the Helsinki Metropolitan Area Council (YTV).

Twenty-four hour mean values of pollutants (from noon to noon) were used in the analyses. Lag0 was defined as the $24 \mathrm{~h}$ period ending on the noon of the day when the PEF was measured. Five-day average was defined as a mean of lag0- $\operatorname{lag} 4$.

To ensure the reliability of the reported PEF data, the following procedures were used. The highest of the three consecutive PEF-values was accepted for the analysis only if it was within $10 \%$ of the next highest value. If the difference was greater than $10 \%$, the median value was chosen. The first four days of data for PEF of each participant were omitted to control for a possible "learning effect" in the manoeuvre.

Daily mean peak flow deviation (PEF deviation, separately for morning, afternoon and evening), daily symptom prevalence and daily mean use of bronchodilators were used as dependent variables in the analyses. For PEF analysis, the individual means were first calculated separately for morning, afternoon and evening PEF. Then individual means were subtracted from the individual daily values of PEF to get an individual daily deviation. Finally, a daily group mean (PEF deviation) for these individual deviations was calculated. For symptom analysis, a daily binary variable (symptoms/no symptoms) for each individual and each symptom was derived. A subject was coded to have an asthmatic symptom if any of the following symptoms were present on a given day: woken by breathlessness, breathlessness, wheezing, or an attack involving breathlessness and wheezing. Daily prevalences were calculated by dividing the sum of subjects with symptoms by the number of subjects answering that day. 
Data were obtained on influenza activity from the Helsinki City Health Authorities and pollen counts from the Finnish Aerobiology Group [12] to control for potential confounding. Influenza activity was reported to be increased during the end of January and beginning of February. However, no serious epidemics were reported. Fever reporting was not increased during that period in the study group. Pollen counts were negligible during the whole study period and were not considered as confounders.

Preliminary analysis was done using a linear regression with only individual pollutants or meteorological variables and their lags up to three days as independent variables. Linearity was examined from scatter plots of PEF deviation versus variables. The preliminary analysis and visualisation of data were done with S-Plus 4.0 (Mathsoft Inc., Cambridge, MA, U.S.A.).

The final regression model was determined by including all the covariates associated with PEF deviation that changed the estimate of the pollutant in the model. The time trend used in the final model was the most parsimonious trend that did not leave any visually observable trend in the residual plot.

Final analyses were done using a first order autoregressive linear model to model for each PEF deviation and symptom score individually. The model for PEF deviation included a continuous variable of temperature and relative humidity, a day of study variable, day of study squared and a binary dummy variable to adjust for weekends. The model for symptom prevalence and bronchodilator use was adjusted for day of study, day of study squared, minimum temperature, minimum temperature squared, relative humidity, relative humidity squared and weekends. The models were weighted with daily numbers of participants to account for the differences in the number of participants between different days. Residual plots for the individual pollutants were examined for potential outliers and heteroscedasticity. The final analyses were done with Statistical Analysis Software (SAS) (SAS Institute Inc., Cary, NC, U.S.A.).

The study was approved by the ethics committees of the Skin and Allergy Hospital at Helsinki and the National Public Health Institute. Written informed consent was obtained from all of the participants. The procedures used in the study were in accordance with the Helsinki Declaration.

\section{Results}

Daily PEF deviations ranged between $-13.2 \mathrm{~L} \cdot \mathrm{min}^{-1}$ and $12.1 \mathrm{~L} \cdot \mathrm{min}^{-1}$ (table 1) while the group means (SD) for morning, day and afternoon PEFs were 420 (105) $\mathrm{L} \cdot \mathrm{min}^{-1}, 437$ (99) $\mathrm{L} \cdot \mathrm{min}^{-1}, 435$ (101) L.min ${ }^{-1}$. The subjects used a mean (SD) of 4.6 (0.5) dosesperson $^{-1} \cdot$ day $^{-1}$ of inhaled bronchodilators and 3.7 (0.2) doses $\cdot$ person $^{-1} \cdot$ day $^{-1}$ inhaled or oral corticosteroids (table 1). Daily mean (SD) symptom prevalence for asthmatic symptoms was $32.1 \%(6.7 \%)$. The mean age of the 57 subjects was 53 yrs. In the skin-prick test 20 out of $53(38 \%)$ subjects tested had a reaction of $3 \mathrm{~mm}$ or more to at least one allergen. In the methacholine challenge 11 out of $34(32 \%)$ subjects tested reacted with at least $20 \%$ bronchoconstriction (provocative dose causing a $20 \%$ fall in forced expired volume in one second (PD20)) to methacholine doses $<2600 \mu \mathrm{g}$.

There was only a weak correlation between particle mass (PM10) and PNC (table 2). Time series indicate that high number concentration, but low mass is typical for particulate pollution in midwinter, and the opposite is true for spring (fig. 1). Minimum temperature was negatively correlated with PNC. Relative humidity was negatively correlated with coarse particles (PM10, PM2.5-10) and positively correlated with PM2.5 and PM1.

Table 1. -Descriptive statistics of the study variables during November 1996-April 97

\begin{tabular}{|c|c|c|c|c|c|c|}
\hline & Days & Min & $25 \%$ & Median & $75 \%$ & $\operatorname{Max}$ \\
\hline Morning PEF deviation $\mathrm{L} \cdot \mathrm{min}^{-1}$ & 181 & -12.6 & -3.3 & 0.4 & 3.3 & 10.2 \\
\hline Afternoon PEF deviation $\mathrm{L} \cdot \mathrm{min}^{-1}$ & 181 & -13.2 & -2.2 & -0.1 & 2.4 & 9.6 \\
\hline Evening PEF deviation $\mathrm{L} \cdot \mathrm{min}^{-1}$ & 181 & -12.6 & -2.7 & -0.7 & 3.0 & 12.1 \\
\hline Cough prevalence $\%$ & 181 & 17.5 & 25.0 & 29.4 & 34.7 & 48.0 \\
\hline Asthma symptom prevalence $\%$ & 181 & 14.9 & 27.1 & 31.9 & 35.7 & 52.5 \\
\hline Bronchodilator use doses $\cdot$ person ${ }^{-1} \cdot$ day $^{-1}$ & 181 & 3.3 & 4.3 & 4.6 & 4.8 & 5.8 \\
\hline $\mathrm{PM} 10 \mu \mathrm{g} \cdot \mathrm{m}^{-3}$ & 169 & 3.8 & 10.2 & 13.5 & 19.5 & 73.7 \\
\hline $\mathrm{PM} 2.5-10 \mu \mathrm{g} \cdot \mathrm{m}^{-3}$ & 164 & 0.8 & 2.8 & 4.7 & 8.9 & 49.3 \\
\hline $\mathrm{PM} 2.5 \mu \mathrm{g} \cdot \mathrm{m}^{-3}$ & 169 & 2.4 & 5.5 & 8.4 & 12.1 & 38.3 \\
\hline PM1 $\mu \mathrm{g} \cdot \mathrm{m}^{-3}$ & 170 & 1.0 & 3.4 & 5.6 & 7.5 & 22.9 \\
\hline $\mathrm{PNC} 1000 \cdot \mathrm{cm}^{-3}$ & 151 & 3.8 & 11.2 & 15.6 & 18.5 & 48.9 \\
\hline $\mathrm{NC} 0.01-0.1 \quad 1000 \cdot \mathrm{cm}^{-3}$ & 151 & 3.7 & 10.4 & 14.5 & 17.7 & 46.5 \\
\hline $\mathrm{NC} 0.1-1 \quad 1000 \cdot \mathrm{cm}^{-3}$ & 151 & 0.1 & 0.6 & 0.8 & 1.2 & 2.8 \\
\hline $\mathrm{CO} \mathrm{mg} \cdot \mathrm{m}^{-3}$ & 177 & 0.1 & 0.3 & 0.4 & 0.5 & 1.1 \\
\hline $\mathrm{NO} \mu \mathrm{g} \cdot \mathrm{m}^{-3}$ & 180 & 3.7 & 10.8 & 15.7 & 22.5 & 146.1 \\
\hline $\mathrm{NO}_{2} \mu \mathrm{g} \cdot \mathrm{m}^{-3}$ & 180 & 8.5 & 20.4 & 25.3 & 31.9 & 67.6 \\
\hline Temperature ${ }^{\circ} \mathrm{C}$ & 178 & -20.3 & -3.4 & 0.3 & 2.8 & 8.8 \\
\hline Relative huimidity $\%$ & 168 & 40.1 & 76.6 & 87.5 & 93.5 & 99.2 \\
\hline
\end{tabular}

PM1: particle mass concentration $<1 \mu \mathrm{m}$; PM2.5: particle mass concentration $<2.5 \mu \mathrm{m}$; PM10: particle mass concentration $<10 \mu \mathrm{m}$; PM2.5 - 10: coarse particle mass (PM10-PM2.5); PNC: daily mean particle number concentration; NC0.01-0.1: number concentration in size range $0.01 \mu \mathrm{m}-0.1 \mu \mathrm{m}$; NC0.1-1: number concentration in size range $0.1 \mu \mathrm{m}-1 \mu \mathrm{m}$; $\mathrm{CO}$ : carbon monoxide; NO: nitric oxide; $\mathrm{NO}_{2}$ : nitrogen dioxide; Min: minimum value; Max: maximum value. 
Table 2. - Spearman correlation coefficients for pollutants and meteorological variables

\begin{tabular}{|c|c|c|c|c|c|c|c|c|c|c|c|c|}
\hline & PM10 & PM2.5-10 & PM2.5 & PM1 & $\mathrm{PNC}$ & $\mathrm{NC} 0.01-0.1$ & $\mathrm{NC} 0.1-1$ & $\mathrm{CO}$ & $\mathrm{NO}$ & $\mathrm{NO}_{2}$ & Temperature & $\begin{array}{l}\text { Relative } \\
\text { humidity }\end{array}$ \\
\hline PM10 & 1.00 & 0.75 & 0.75 & 0.63 & 0.26 & 0.24 & 0.57 & -0.03 & 0.15 & 0.16 & 0.21 & -0.15 \\
\hline PM2.5-10 & & 1.00 & 0.19 & 0.11 & 0.13 & 0.13 & 0.06 & -0.30 & -0.01 & 0.07 & 0.19 & -0.50 \\
\hline $\mathrm{PM} 2.5$ & & & 1.00 & 0.92 & 0.30 & 0.26 & 0.85 & 0.32 & 0.29 & 0.23 & 0.10 & 0.31 \\
\hline PM1 & & & & 1.00 & 0.36 & 0.32 & 0.86 & 0.39 & 0.38 & 0.32 & -0.07 & 0.30 \\
\hline $\mathrm{PNC}$ & & & & & 1.00 & 1.00 & 0.59 & 0.44 & 0.77 & 0.81 & -0.33 & -0.08 \\
\hline $\mathrm{NC} 0.01-0.1$ & & & & & & 1.00 & 0.55 & 0.43 & 0.76 & 0.81 & -0.35 & -0.10 \\
\hline $\mathrm{NC} 0.1-1$ & & & & & & & 1.00 & 0.47 & 0.57 & 0.51 & -0.05 & 0.30 \\
\hline $\mathrm{CO}$ & & & & & & & & 1.00 & 0.60 & 0.44 & -0.15 & 0.48 \\
\hline NO & & & & & & & & & 1.00 & 0.73 & -0.28 & 0.07 \\
\hline $\mathrm{NO}_{2}$ & & & & & & & & & & 1.00 & -0.39 & -0.08 \\
\hline Temperature & & & & & & & & & & & 1.00 & 0.19 \\
\hline $\begin{array}{l}\text { Relative } \\
\text { humidity }\end{array}$ & & & & & & & & & & & & 1.00 \\
\hline
\end{tabular}

PM1: particle mass concentration $<1 \mu \mathrm{m}$; PM2.5: particle mass concentration $<2.5 \mu \mathrm{m}$; PM10: particle mass concentration $<10 \mu \mathrm{m}$; PM2.5-10: coarse particle mass (PM10-PM2.5); PNC: daily mean particle number concentration; NC0.01-0.1: number concentration in size range $0.01 \mu \mathrm{m}-0.1 \mu \mathrm{m}$; NC0.1-1: number concentration in size range $0.1 \mu \mathrm{m}-1 \mu \mathrm{m}$; $\mathrm{CO}$ : carbon monoxide; $\mathrm{NO}$ : nitric oxide; $\mathrm{NO}_{2}$ : nitrogen dioxide. All coefficients above 0.15 or below -0.15 are statistically significant at $\mathrm{p}<0.05$.
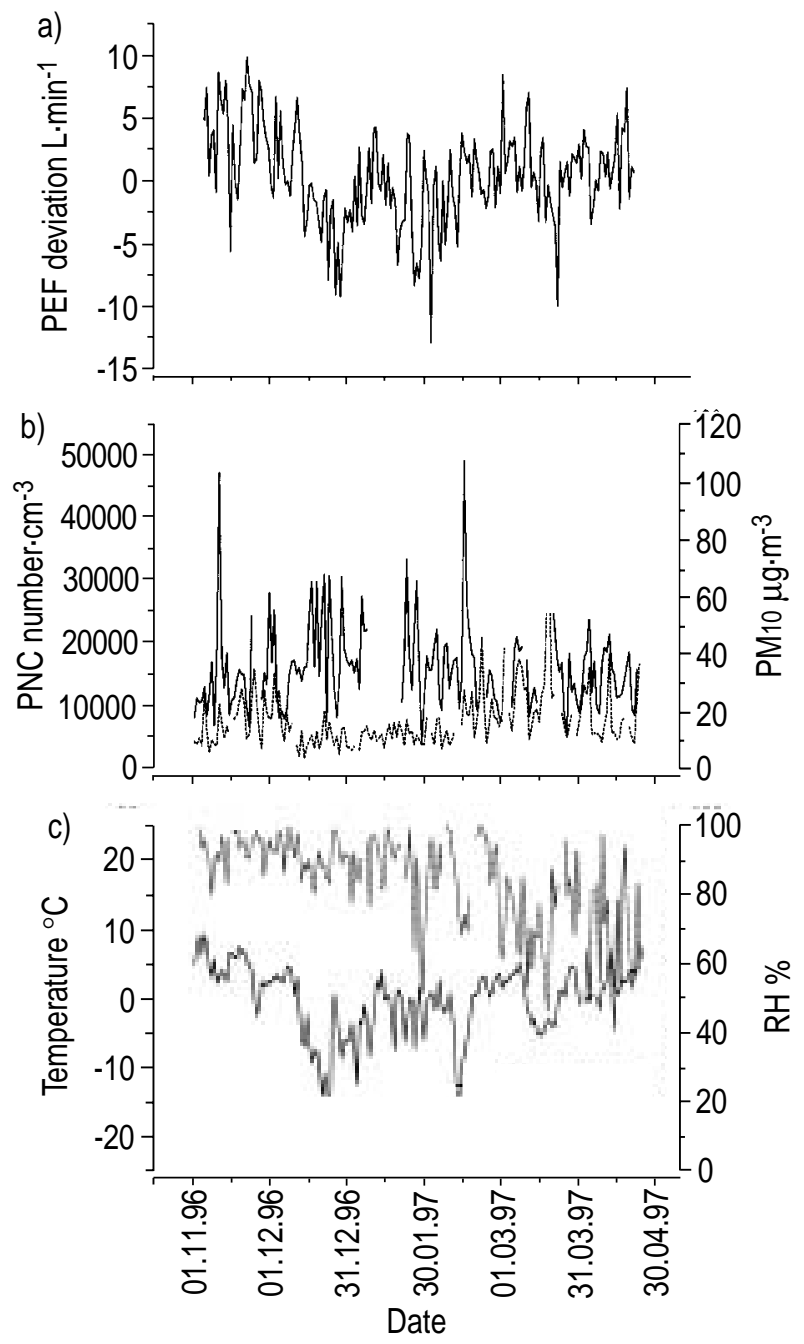

Fig. 1. - Time series of afternoon peak expiratory flow (PEF) deviation (a), particle number concentration (PNC; - ) and particle mass $<10 \mu \mathrm{m}$ (PM10; - - -) (b), minimum temperature $(-)$ and relative humidity $(\mathrm{RH} ;-.--)(\mathrm{c})$.
The mass measurements of particles in the coarse size range (PM10, PM2.5-10) were positively associated with PEF deviation (table 3). PM10 (3-day lag) was associated with increased bronchodilator use. However, the residuals from the regression models for PM10 and PM2.5-10 did not have a constant variance, which is probably due to an underlying seasonal influence (fig. 2). The apparent positive association between PM10 and PEF deviation was mainly due to the spring season. Also, further inclusion of the third and fourth power of the day of study variable in the regression models reduced the effect estimates of PM10, but had little effect on the effect estimates of PNC.

Daily mean number concentrations of particulate matter were significantly negatively associated with daily morning (lag1), afternoon (lag0, lag2) and evening (lag0, lag3) PEF deviations (table 3). This effect was also observed with lagged 5-day averages of PNC's (afternoon and evening PEF). The strongest and most significant effect estimates were seen in size classes below $0.1 \mu \mathrm{m}$ (table 4 ), which were also most strongly correlated with total particle number counts (fig. 3). No statistically significant associations between particulate pollution and respiratory symptoms was detected.

Traffic-related gaseous pollutants $\left(\mathrm{CO}, \mathrm{NO}, \mathrm{NO}_{2}\right)$ were negatively associated with daily morning (lag2) and evening (lag1) PEF rates (table 5). Two-pollutant models, including a traffic-related gaseous pollutant and PNC, generally reduced the effect estimates of both pollutants and increased the standard errors (table 6).

Sensitivity analyses were also undertaken with several models to ensure the stability of results. Analyses were done with regression models including one of the following: a dummy variable for holidays, a variable indicating exposure to passive tobacco smoke, a variable indicating time spent outdoors, bronchodilator use and its interaction with particulates. A dichotomised (medication/no medication) variable was also used to derive the dependent variable in the medication models. A LOESS (locally weighted regression smoothing) function was used for time 
Table 3. - The adjusted associations of particle number and mass concentrations with health outcomes

\begin{tabular}{|c|c|c|c|c|c|c|c|c|c|c|c|}
\hline & & \multicolumn{2}{|c|}{ PM10 } & \multicolumn{2}{|c|}{ PM2.5-10 } & \multicolumn{2}{|c|}{$\mathrm{PM} 2.5$} & \multicolumn{2}{|c|}{ PM1 } & \multicolumn{2}{|c|}{$\mathrm{PNC}$} \\
\hline & & $\beta$ & SEM & $\beta$ & SEM & $\beta$ & SEM & $\beta$ & SEM & $\beta$ & SEM \\
\hline \multirow[t]{5}{*}{ Morning PEF deviation $\mathrm{L} \cdot \mathrm{min}^{-1}$} & $\operatorname{lag} 0$ & 0.67 & $0.31^{*}$ & 0.70 & $0.30 *$ & 0.45 & 0.37 & 0.13 & 0.36 & -0.10 & 0.30 \\
\hline & lag1 & -0.12 & 0.31 & 0.15 & 0.32 & -0.40 & 0.37 & -0.47 & 0.35 & -0.77 & $0.30 *$ \\
\hline & lag2 & 0.07 & 0.31 & 0.23 & 0.31 & -0.08 & 0.36 & -0.14 & 0.35 & 0.11 & 0.32 \\
\hline & lag3 & 0.44 & 0.34 & 0.64 & 0.34 & -0.01 & 0.38 & 0.11 & 0.35 & -0.24 & 0.33 \\
\hline & 5-d ave & 1.74 & $0.60 * *$ & 1.42 & $0.44 * *$ & 0.56 & 0.53 & 0.38 & 0.60 & -0.98 & 0.59 \\
\hline \multirow[t]{5}{*}{ Afernoon PEF deviation $\mathrm{L} \cdot \mathrm{min}^{-1}$} & $\operatorname{lag} 0$ & 0.05 & 0.31 & 0.31 & 0.30 & -0.18 & 0.40 & -0.52 & 0.38 & -0.66 & $0.33^{*}$ \\
\hline & lag1 & 0.49 & 0.30 & 0.47 & 0.30 & 0.39 & 0.38 & 0.23 & 0.36 & -0.03 & 0.34 \\
\hline & lag2 & 0.09 & 0.30 & 0.25 & 0.30 & -0.12 & 0.37 & -0.37 & 0.36 & -0.81 & $0.36^{*}$ \\
\hline & lag3 & 0.14 & 0.35 & 0.08 & 0.36 & 0.15 & 0.40 & -0.01 & 0.38 & -0.29 & 0.35 \\
\hline & 5-d ave & 0.59 & 0.56 & 0.49 & 0.46 & 0.20 & 0.45 & -0.43 & 0.51 & -1.92 & $0.59 * *$ \\
\hline \multirow[t]{5}{*}{ Evening PEF deviation $\mathrm{L} \cdot \mathrm{min}^{-1}$} & lag0 & 0.50 & 0.33 & 0.73 & $0.32 *$ & 0.09 & 0.40 & -0.22 & 0.40 & -0.92 & $0.35^{* *}$ \\
\hline & lag1 & 0.58 & 0.34 & 0.62 & 0.34 & 0.36 & 0.41 & 0.35 & 0.39 & 0.11 & 0.36 \\
\hline & lag2 & 0.18 & 0.34 & 0.31 & 0.35 & 0.07 & 0.41 & -0.33 & 0.39 & 0.09 & 0.36 \\
\hline & lag3 & -0.52 & 0.37 & -0.49 & 0.39 & -0.54 & 0.41 & -0.74 & 0.38 & -0.80 & $0.35^{*}$ \\
\hline & 5-d ave & 0.97 & 0.73 & 0.84 & 0.62 & 0.14 & 0.57 & 0.02 & 0.69 & -1.48 & $0.73^{*}$ \\
\hline \multirow[t]{5}{*}{ Asthma symptom prevalence $\%$} & lag0 & 0.001 & 0.004 & -0.003 & 0.004 & 0.007 & 0.005 & 0.006 & 0.005 & 0.002 & 0.004 \\
\hline & lag1 & -0.002 & 0.004 & 0.004 & 0.004 & -0.007 & 0.005 & -0.006 & 0.005 & -0.003 & 0.004 \\
\hline & lag2 & 0.003 & 0.005 & 0.005 & 0.005 & -0.001 & 0.005 & -0.002 & 0.005 & 0.004 & 0.005 \\
\hline & lag3 & -0.008 & 0.005 & -0.004 & 0.005 & -0.008 & 0.005 & -0.008 & 0.005 & -0.001 & 0.005 \\
\hline & 5-d ave & -0.008 & 0.010 & -0.002 & 0.007 & -0.004 & 0.007 & 0.000 & 0.008 & 0.000 & 0.009 \\
\hline \multirow[t]{5}{*}{ Cough prevalence $\%$} & $\operatorname{lag} 0$ & 0.003 & 0.004 & 0.000 & 0.004 & 0.003 & 0.005 & 0.004 & 0.005 & 0.004 & 0.004 \\
\hline & lag1 & -0.007 & 0.004 & -0.006 & 0.004 & -0.007 & 0.005 & -0.003 & 0.004 & -0.001 & 0.004 \\
\hline & lag2 & -0.007 & 0.004 & -0.008 & 0.004 & -0.007 & 0.005 & -0.006 & 0.004 & 0.004 & 0.004 \\
\hline & lag3 & -0.002 & 0.004 & -0.003 & 0.004 & 0.001 & 0.004 & 0.005 & 0.004 & 0.002 & 0.004 \\
\hline & 5-d ave & -0.010 & 0.010 & -0.010 & 0.007 & -0.004 & 0.007 & 0.005 & 0.009 & 0.012 & 0.010 \\
\hline \multirow{5}{*}{$\begin{array}{l}\text { Bronchodilator use } \\
\text { doses } \cdot \text { person }^{-1} \cdot \text { day }^{-1}\end{array}$} & lag0 & -0.028 & 0.025 & -0.041 & 0.027 & -0.014 & 0.030 & -0.011 & 0.027 & -0.013 & 0.023 \\
\hline & lag1 & -0.002 & 0.026 & -0.035 & 0.026 & 0.031 & 0.031 & 0.008 & 0.028 & 0.020 & 0.023 \\
\hline & lag2 & -0.046 & 0.026 & -0.032 & 0.028 & -0.055 & 0.029 & -0.016 & 0.029 & -0.017 & 0.023 \\
\hline & lag3 & 0.058 & $0.027 *$ & 0.048 & 0.030 & 0.043 & 0.030 & 0.014 & 0.028 & -0.009 & 0.024 \\
\hline & 5-d ave & -0.025 & 0.070 & -0.031 & 0.053 & 0.018 & 0.052 & -0.027 & 0.062 & -0.029 & 0.059 \\
\hline
\end{tabular}

The models are adjusted for long term time trend, temperature, relative humidity, weekend effect and autocorrelation. PM1: particle mass concentration $<1 \mu \mathrm{m}$; PM2.5: particle mass concentration $<2.5 \mu \mathrm{m}$; PM10: particle mass concentration $<10 \mu \mathrm{m}$; PM2.5-10: coarse particle mass (PM10-PM2.5); PNC: daily mean particle number concentration; PEF: peak expiratory flow; $\beta$ : regression coefficient (calculated for interquartile range of pollutant); 5 -d ave: 5 day average; ${ }^{*} \mathrm{p}<0.05$; $* *: \mathrm{p}<0.01$.

trend in S-Plus. PM10, PM2.5-10, PM2.5 and PM1 models were also restricted to only those days with data on PNC. The conclusions from all these models were the same as those presented.

\section{Discussion}

Daily mean number concentration of particles, but not particle mass (PM10, PM2.5-10, PM2.5, PM1) was negatively associated with daily PEF deviations. Particle number concentrations in the size range smaller than $0.1 \mu \mathrm{m}$ had the strongest effects. Daily mean number concentration is dominated by the numerous particles in these smallest size ranges. Daily concentrations of all particulate and gaseous pollutants, except PNC, were low when compared to current air quality standards or other urban locations during the present study. PNCs were comparable to levels measured in previous studies. The current observations agree with the human health studies published on the effects of PNCs [7, 8, 13]. The effect estimates were smaller in the present study than in the other study on adult asthmatics, conducted in Erfurt [8]. This may reflect smaller variation in PEF measurements in the present study group. The smaller variation in PEF could be due to heavy medication and possibly better asthma control in the present study group. In addition, the composition of particulate matter may be different between Erfurt and Helsinki.

In a previous study, both PNC and particle mass were negatively associated with $\mathrm{PEF}$ in a group of asthmatic children [14]. This previous study was done in Kuopio, Finland during mid-winter, when resuspended road dust did not have any significant effect on the particle mass measurements. Therefore, the findings of this paper and the previous study [14] are both consistent with an adverse effect on PEF by combustion particles, but less of an effect by resuspended particles.

Several toxicological studies have shown that particles cause inflammatory reaction in vitro and in vivo. Particles collected from the environment cause inflammatory reactions in rat lungs, rat cell lines and human cell lines [15-17]. Free radical activity or oxidative capacity of particulate matter might be essential for provoking these inflammatory responses. There is also evidence suggesting that the bulk of free radical activity is caused by the ultrafine fraction of urban ambient particles [18]. Animal studies have also shown that ultrafine titanium and polytetrafluoroethylene (Teflon) 

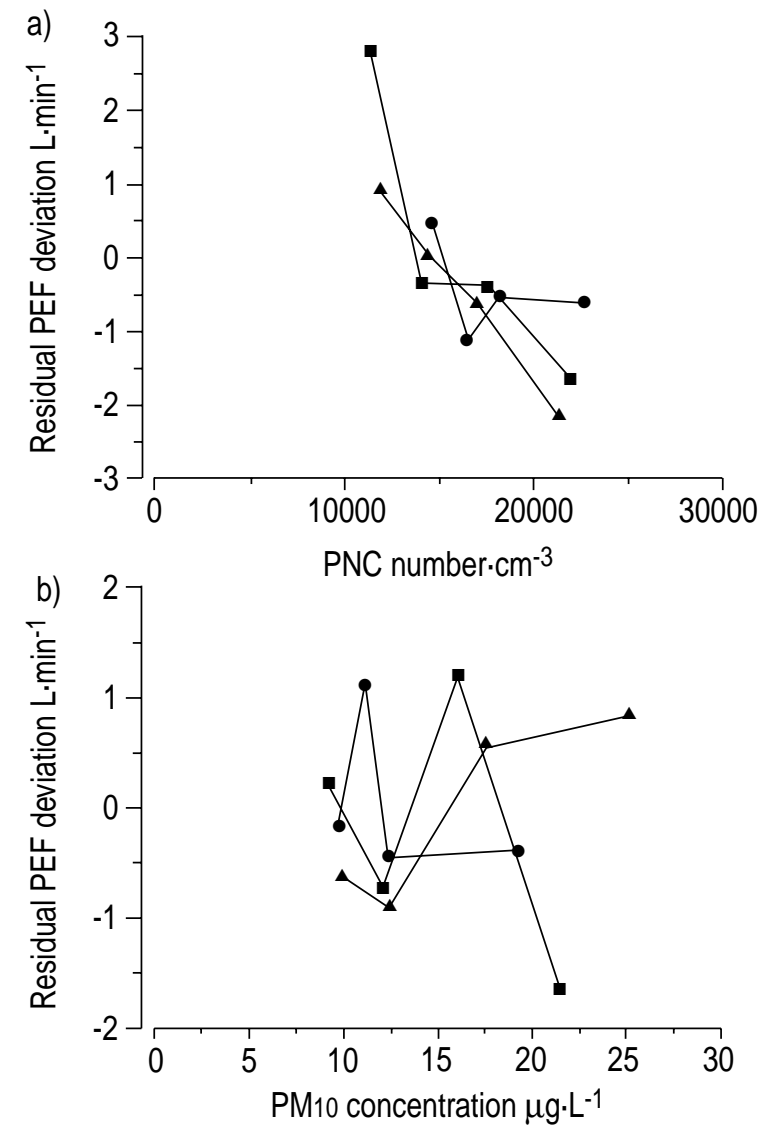

Fig. 2. - Mean residual afternoon peak expiratory flow (PEF) deviations by quartiles of particle number concentration (PNC, 5 -day average (a)) and particle mass $<10 \mu \mathrm{m}$ (PM10, 5-day average (b)) in three seasons. The residuals are obtained from a model including adjustments for time trend, temperature, relative humidity, weekend effect and autocorrelation. $\mathbf{\square}$ : NovemberDecember, ๑: January-February, $\boldsymbol{\Delta}$ : March-April.

Table 4. - The adjusted associations of particle number concentrations in two size ranges $(0.01-0.1 \mu \mathrm{m}$ and $0.1-1 \mu \mathrm{m}$ ) with peak flow deviations

\begin{tabular}{|c|c|c|c|c|c|}
\hline \multirow{2}{*}{\multicolumn{2}{|c|}{ Peak flow deviation $\mathrm{L} \cdot \mathrm{min}^{-1}$}} & \multicolumn{2}{|c|}{$\mathrm{NC} 0.01-0.1$} & \multicolumn{2}{|c|}{$\mathrm{NC} 0.1-1$} \\
\hline & & $\beta$ & SEM & $\beta$ & $\overline{\text { SEM }}$ \\
\hline \multirow[t]{4}{*}{ Morning } & lag0 & -0.10 & 0.32 & -0.17 & 0.34 \\
\hline & lag1 & -0.83 & $0.31 * *$ & -0.42 & 0.35 \\
\hline & lag2 & 0.11 & 0.34 & 0.09 & 0.36 \\
\hline & 5-day average & -1.49 & 0.84 & -0.09 & 0.95 \\
\hline \multirow[t]{4}{*}{ Afternoon } & lag0 & -0.69 & 0.35 & -0.61 & 0.38 \\
\hline & la & -0.04 & 0.3 & 0.07 & 0.39 \\
\hline & lag & -0.82 & $0.37 *$ & -0.98 & $0.40 *$ \\
\hline & 5-day average & -2.77 & $0.86^{* *}$ & -2.00 & $1.00^{*}$ \\
\hline \multirow[t]{4}{*}{ Evening } & 0 & -0.96 & 0.3 & -0.77 & 0.4 \\
\hline & lag1 & 0.10 & 0.37 & 0.29 & 0.41 \\
\hline & lag2 & 0.13 & 0.38 & -0.38 & 0.41 \\
\hline & 5-day average & -2.24 & $0.98 *$ & -1.55 & 1.11 \\
\hline
\end{tabular}

The models are adjusted for long term time trend, temperature, relative humidity, weekend effect and autocorrelation. $\mathrm{NC} 0.01-0.1$ : number concentration in size range $0.01-0.1 \mu \mathrm{m} ; \mathrm{NC} 0.1-1$ : number concentration in size range $0.1-1 \mu \mathrm{m} ; \beta$ : regression coefficient (calculated for interquartile range of pollutant). ${ }^{*}: \mathrm{p}<0.05 ; *$ p $<0.01$.
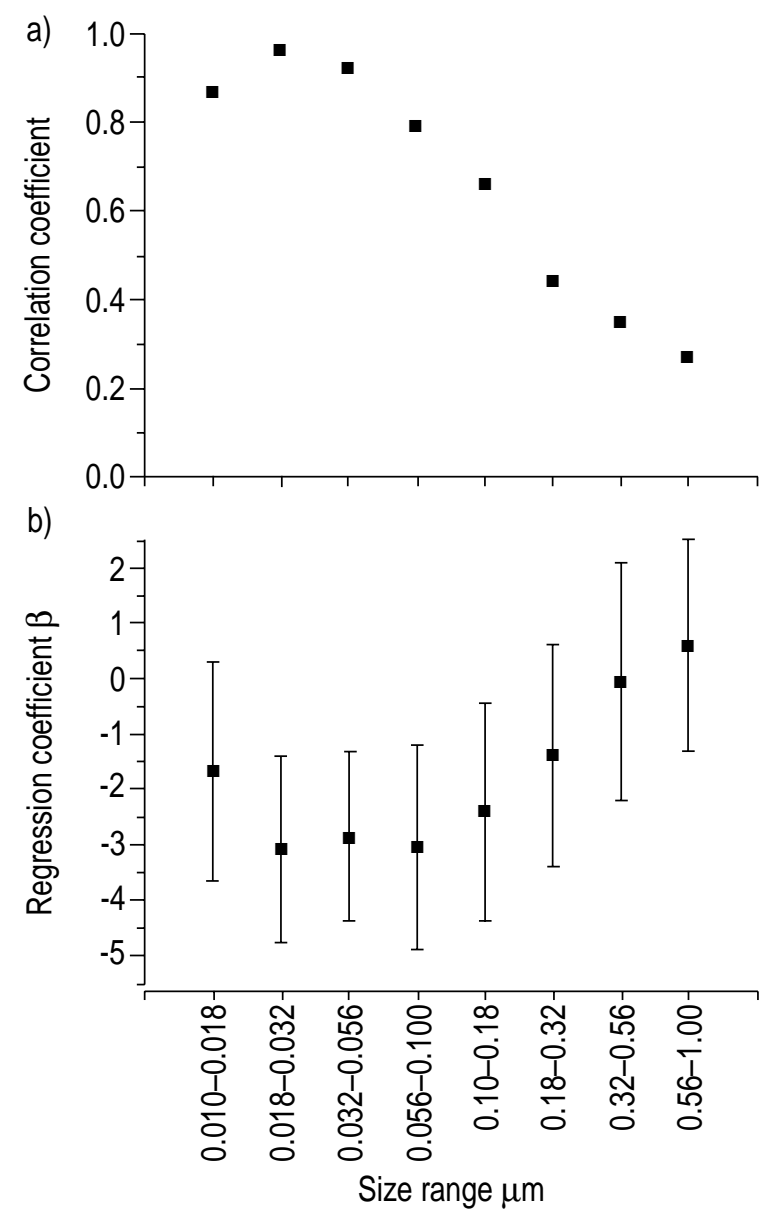

Fig. 3. - a) Adjusted regression coefficients $(\beta)$ with $95 \%$ confidence intervals for particle number concentrations (lag1) in 8 size classes and b) their correlation with total number concentrations. The dependent variable in the model is afternoon peak expiratory flow deviation and adjustments are made for time trend, temperature, relative humidity and weekend effect and autocorrelation.

particles can cause inflammatory responses in rat lungs $[19,20]$.

The oxidative capacity of particulate matter could be mediated by the substances attached to fine and ultrafine carbon particles. Carbon particles derived from combustion processes are the most numerous particles in the ultrafine range. Carbon particles aggregate easily into clusters containing substances like iron, other transition metals, volatile organic compounds and polycyclic aromatic hydrocarbons, which all have been associated with the inflamnmatory reaction caused by particles [18-22]. It has also been suggested that the inflammatory properties of ultrafine particles are mediated by their large numbers, small size and high penetration rate into the interstitium, independently of their chemical composition [23].

In the present data, mass measurements of particulate matter (PM10, PM2.5-10, PM2.5, and PM1) were strongly influenced by road dust. The road dust phenomenon is typical for subarctic weather conditions where the roads are sanded in the winter for traffic safety and the use of studded tyres is common [24]. 
Table 5. - The adjusted associations of gaseous pollutant concentrations with peak flow deviations

\begin{tabular}{|c|c|c|c|c|c|c|c|}
\hline \multirow{2}{*}{\multicolumn{2}{|c|}{ Peak flow deviation $\mathrm{L} \cdot \mathrm{min}^{-1}$}} & \multicolumn{2}{|c|}{$\mathrm{CO}$} & \multicolumn{2}{|c|}{ NO } & \multicolumn{2}{|c|}{$\mathrm{NO}_{2}$} \\
\hline & & $\beta$ & SEM & $\beta$ & SEM & $\beta$ & SEM \\
\hline \multirow[t]{4}{*}{ Morning } & $\operatorname{lag} 0$ & 0.27 & 0.38 & 0.13 & 0.14 & 0.14 & 0.30 \\
\hline & lag1 & -1.08 & $0.36 * *$ & -0.37 & $0.14 *$ & -0.64 & $0.29 *$ \\
\hline & lag2 & 0.23 & 0.38 & -0.03 & 0.15 & 0.24 & 0.32 \\
\hline & 5-day average & -1.11 & 1.19 & -0.68 & 0.43 & -0.46 & 0.77 \\
\hline \multirow{4}{*}{ Afternoon } & $\operatorname{lag} 0$ & -0.40 & 0.43 & -0.20 & 0.16 & -0.25 & 0.32 \\
\hline & lag1 & -0.13 & 0.41 & 0.06 & 0.16 & 0.03 & 0.32 \\
\hline & $\operatorname{lag} 2$ & -0.71 & 0.41 & -0.36 & 0.16 & -0.40 & 0.34 \\
\hline & 5-day average & -3.03 & $1.06 * *$ & -1.25 & $0.37 * *$ & -1.18 & 0.70 \\
\hline \multirow{4}{*}{ Evening } & $\operatorname{lag} 0$ & -0.70 & 0.45 & -0.26 & 0.17 & -0.75 & $0.34^{*}$ \\
\hline & lag1 & -0.31 & 0.44 & 0.01 & 0.17 & -0.02 & 0.34 \\
\hline & lag2 & 0.30 & 0.44 & -0.17 & 0.18 & 0.25 & 0.36 \\
\hline & 5-day average & -3.62 & $1.19 * *$ & -1.44 & $0.42 * * *$ & -1.49 & 0.80 \\
\hline
\end{tabular}

The models are adjusted for long term time trend, temperature, relative humidity, weekend effect and autocorrelation. $\mathrm{CO}$ : carbon monoxide; $\mathrm{NO}$ : nitric oxide; $\mathrm{NO}_{2}$ : nitrogen dioxide; $\beta$ : regression coefficient (calculated for interquartile range of pollutant); $*$ : $<<0.05 ; * *: \mathrm{p}<0.01 ; * * *: \mathrm{p}<0.001$

Highest PM10 levels due to resuspended road dust are observed in late fall and early spring, when snow cover does not prevent resuspension. A large amount of evidence exists on the negative health effects of particulate matter mass measured by impactors $[1,14,21]$. However, this study was not able to show any significant negative associations of PM10, PM2.5-10, PM2.5 or PM1 with PEF deviations. In the linear regression models PM10, PM2.5-10 and PM2.5 were positively associated with PEF deviation, but the residuals of the models did not have constant variance and the models were somewhat sensitive to adjustments for time trend. This may be due to the seasonal differences in the composition of particulate matter observed in the present study, or it may reflect the relatively low levels and low variation of particulate mass in the present study. Only very limited conclusions can therefore be drawn from the linear regression models of PM10 or PM2.5-10 in table 3.

In previous studies, mass measurements of particulate matter may have been surrogates for total number concentration, as the correlation between PM10 and number concentrations are, in general, relatively strong $[7,8]$. In contrast, in the present study, the correlation coefficients for mass measurements and PNC were 0.40
(PM1), 0.30 (PM2.5) and 0.30 (PM10). This low correlation is probably explained by the road dust phenomenon i.e. in the present study, variation in coarse particle concentrations was dominated by resuspended dust, not combustion sources.

In the present study, PNC was correlated with traffic generated gaseous pollutants. These pollutants were also associated with decreases in PEF rates although the associations tended to be less significant than those of PNC and also, except for the 5-day average of CO, smaller in magnitude. Due to the intercorrelation of the pollutants, it is difficult to distinguish the respiratory effects of PNC from that of $\mathrm{CO}$ or $\mathrm{NO}_{\mathrm{x}}$. Two-pollutant models including either $\mathrm{CO}, \mathrm{NO}$ or $\mathrm{NO}_{2}$ and $\mathrm{PNC}$ generally decreased the effect estimates and increased the standard errors for both pollutants included in the model.

The present results show that particle number concentrations in ambient air, especially in the ultrafine range, are negatively associated with the respiratory health of adult asthmatics. The effects of ultrafine particles could not be definitely separated from the effects of other traffic generated pollutants, namely oxides of nitrogen and carbon monoxide. In this study, no negative effect of particle mass was seen, probably

Table 6. - The adjusted associations of pollutant concentrations with peak flow deviations from three regression models including two pollutants

\begin{tabular}{|c|c|c|c|c|c|c|c|}
\hline \multirow{2}{*}{\multicolumn{2}{|c|}{ Peak flow deviation $\mathrm{L} \cdot \mathrm{min}^{-1}$}} & \multicolumn{2}{|c|}{ Morning } & \multicolumn{2}{|c|}{ Afternoon } & \multicolumn{2}{|c|}{ Evening } \\
\hline & & \multirow{2}{*}{$\begin{array}{c}\beta \\
-0.67 \\
-0.44\end{array}$} & \multirow{2}{*}{$\begin{array}{c}\text { SEM } \\
0.64 \\
0.44\end{array}$} & \multirow{2}{*}{$\begin{array}{c}\beta \\
-0.46 \\
-0.46\end{array}$} & \multirow{2}{*}{$\begin{array}{c}\text { SEM } \\
0.69 \\
0.48\end{array}$} & \multirow{2}{*}{$\begin{array}{c}\beta \\
-0.46 \\
-0.72\end{array}$} & \multirow{2}{*}{$\begin{array}{c}\text { SEM } \\
0.73 \\
0.50\end{array}$} \\
\hline Model 1 & $\begin{array}{l}\mathrm{CO}^{\#} \\
\mathrm{PNC}\end{array}$ & & & & & & \\
\hline Model 2 & $\begin{array}{l}\text { NO } \\
\text { PNC }\end{array}$ & $\begin{array}{l}-0.19 \\
-0.51\end{array}$ & $\begin{array}{l}0.35 \\
0.59\end{array}$ & $\begin{array}{r}0.09 \\
-0.80\end{array}$ & $\begin{array}{l}0.38 \\
0.65\end{array}$ & $\begin{array}{l}-0.35 \\
-0.44\end{array}$ & $\begin{array}{l}0.41 \\
0.69\end{array}$ \\
\hline Model 3 & $\begin{array}{l}\mathrm{NO}_{2} \\
\mathrm{PNC}\end{array}$ & $\begin{array}{r}0.27 \\
-0.98\end{array}$ & $\begin{array}{l}0.69 \\
0.60\end{array}$ & $\begin{array}{l}-0.28 \\
-0.45\end{array}$ & $\begin{array}{l}0.74 \\
0.67\end{array}$ & $\begin{array}{l}-0.50 \\
-0.56\end{array}$ & $\begin{array}{l}0.78 \\
0.70\end{array}$ \\
\hline
\end{tabular}

The models are adjusted for long term time trend, temperature, relative humidity, weekend effect and autocorrelation. ${ }^{\#}$ : Lag1 of pollutant is used for regression models with morning PEF deviation and lag0 for other deviations. CO: carbon monoxide; NO: nitric oxide; $\mathrm{NO}_{2}$ : nitrogen dioxide; PNC: daily mean particle number concentration; $\beta$ : regression coefficient (calculated for interquartile range of pollutant). 
because variation in particle mass $<10 \mu \mathrm{m}$ concentration was dominated by soil-derived, coarse particles. Current findings suggest that possibly particle number concentrations, in addition to mass measurements with impactors, should be used in air quality monitoring. These results also suggest that high levels of coarse, soilderived particles observed in subarctic climates in the spring are not associated with as severe health effects as traffic generated particles.

Acknowledgements. We thank Mr. S Penttinen and Mr. J Hosiokangas for their commitment in the fieldwork.

\section{References}

1. Dusseldorp A, Kruize H, Brunekreef B, Hofschreuder P, de Meer G, Oudvorst AB. Associations of PM10 and Airborne Iron with Respiratory Health of Adults Living Near a Steel Factory. Am J Respir Crit Care Med 1995; 152: 1932 - 1939.

2. Pope CA III, Dockery DW, Spengler JD, Raizenne ME. Respiratory health and PM10 pollution - a daily time series analysis. Am Rev Respir Dis 1991; 44 $668-674$.

3. Schwartz J, Slater D, Larson T, Pierson WE, Koenig JQ. Particulate air pollution and hospital emergency visits for asthma in Seattle. Am Rev Respir Dis 1993; 147: $826-831$.

4. Dockery DW, Pope CAI, Xu X, et al. An association between air pollution and mortality in six U.S. cities. New Engl J Med 1993; 329: 1753-1759.

5. Vedal S, Petkau J, White R, Blair J. Acute effects of ambient inhalable particles in asthmatic and nonasthmatic children. Am J Respir Crit Care Med 1998; 157: $1034-1043$.

6. Pope CA III, Dockery DW. Acute health effects of PM10 pollution on symptomatic and asymptomatic children. Am Rev Respir Dis 1992; 145: 1123 1128.

7. Pekkanen J, Timonen KL, Ruuskanen J, Reponen A, Mirme A. Effects of Ultrafine and Fine Particles in Urban Air on Peak Expiratory Flow among Children with Asthmatic Symptoms. Environ Res 1997; 74: 24-33.

8. Peters A, Wichmann HE, Tuch T, Heinrich J, Heyder J. Respiratory Effects Are Associated with the Number of Ultrafine Particles. Am J Respir Crit Care Med 1997; 155: 1376-1383.

9. Oberdörster G, Gelein RM, Ferin J, Weiss B. Association of particulate air pollution and acute mortality: Involvement of ultrafine particles? Inhal Toxicol 1995; 7: $111-124$.

10. Buzorius G, Hämeri K, Pekkanen J, Kulmala M.
Spatial variation of aerosol number concentration in Helsinki city. Atmos Env 1999; 33: 553-565.

11. Tuch T, Mirme A, Tamm E, et al. Comparison of two particle size spectrometers for ambient aerosol measurements in environmental epidemiology. Atmos Environ 2000; 34: 139-149.

12. The Finnish Pollen Bulletin 1997; 22.

13. Tiittanen P, Timonen KL, Ruuskanen J, Mirme A, Pekkanen J. Fine particulate air pollution, resuspended road dust and respiratory health among symptomatic children. Eur Respir J 1999; 13: 266-273.

14. Timonen KL, Pekkanen J. Air pollution and respiratory health among children with asthmatic or cough symptoms. Am J Respir Crit Care Med 1997; 156: $546-552$.

15. Vincent R, Bjarnason SG, Adamson IYR, et al. Acute Pulmonary Toxicity of Urban Particulate Matter and Ozone. Am J Pathol 1997; 151: 1563-1570.

16. Becker S, Soukup JM, Gilmour MI, Devlin RB. Stimulation of Human and Rat Alveolar Macrophages by Urban Air Particulates: Effects on Oxidant Radical Generation and Cytokine Production. Toxicol Appl Pharmacol 1996; 141: 637-648.

17. Carter JD, Ghio AJ, Samet JM, Devlin RB. Cytokine Production by Human Airway Epithelial Cells after Exposure to an Air Pollution Particle is Metal-Dependent. Toxicol Appl Pharmacol 1997; 146 $180-188$.

18. Gilmour PS, Brown DM, Lindsay TG, Beswick PH, MacNee W, Donaldson K. Adverse health effects of PM10 particles: involvement of iron in generation of hydroxyl radical. Occup Environ Med 1996; 53: $817-822$.

19. Johnston CJ, Finkelstein JN, Gelein R, Baggs R, Oberdörster G. Characterization of the Early Pulmonary Inflammatory Response Associated with PTFE Fume Exposure. Toxicol Appl Pharmacol 1996; 140: $154-163$.

20. Osier M, Oberdörster G. Intratracheal Inhalation vs. Intratracheal Instillation: Differences in Particle Effects. Fundam Appl Toxicol 1997; 40: 220-227.

21. Vedal S. Ambient Particles and Health: Lines that Divide. J Air Waste Manage Assoc 1997; 47: $551-581$.

22. Venkataraman C, Raymond J. Estimating the lung deposition of particulate polycyclic aromatic hydrocarbons associated with multimodal urban aerosols. Inhal Toxicol 1998; 10: 183-204.

23. Hosiokangas J, Kikas Ü, Pekkanen J, Ruuskanen J, Tammet $\mathrm{H}$. Identifying and quantifying air pollution sources in Kuopio by receptor modelling. J Aerosol Sci 1995; 26: S423-S424.

24. Vallius M, Ruuskanen J, Mirme A, Pekkanen J. Concentrations and estimated soot content of PM1, PM2.5, and PM10 in sub-arctic urban atmosphere. Environ Sci Tech 2000; 34: 1919-1925. 